\title{
Analysis of the Failure of Cylindrical Pressure Vessels
}

\author{
Osama A. Terfas*, Arwa M. Elambrouk, Ahlam Y. Elraqiq \\ Department of marine and offshore engineering, University of Tripoli, Libya
}

DOI: https://doi.org/10.21467/proceedings.4.24

* Corresponding author email: o.terfas@uot.edu.ly

\begin{abstract}
This study investigates the failure of cylindrical pressure vessels and examines their integrity in the presence of cracks using von-Mises (Distortion Energy) yielding criterion and fracture mechanics methodology. The design Code of ASME-VIII section-2 was used to determine safe thickness and maximum allowable working pressure. The fracture stress, the critical stress intensity factor, the critical crack length and maximum pressure were determined. The results showed that yielding criterion with factor of safety of "2" for materials proposed in this study are applicable to design and construct pressure vessels under considered internal pressure and vessel size. The study revealed that cracked pressure vessels can be fit for service under some conditions of crack size and internal pressure. It can be concluded that pressure vessels that are safe under yielding theories could be safe as well where the crack exists under restricted conditions of the applied internal pressure, shell thickness, and material property.

KEYWORDS: Fracture mechanics, pressure vessels, structural integrity, yielding criterion.
\end{abstract}

\section{Introduction}

The continued and prolonged use of pressure vessels for power plants, nuclear reactor vessels, storage vessels for liquefied gases such as LPG or chemical reactions, industrial processing, and oil refineries storage tanks requires them to withstand severe conditions of pressure, temperature, and other environments. Such environmental conditions include corrosion, neutron irradiation, and hydrogen embrittlement. Pressure vessels are required to operate at a temperature as high as $600 \mathrm{C}$ to as low as $-20 \mathrm{C}$, with design pressures as low as $0.1 \mathrm{MPa}$ to as high as $15 \mathrm{MPa}$ [1]. To ensure safe design, installation, operation, and maintenance, the pressure vessels must be in accordance with codes such as American Society of Mechanical Engineers (ASME) Boiler and Pressure Vessel code. Therefore, great emphasis should be placed on analytical and experimental methods for determining their operating stresses [2]. When the pressure vessel is exposed to internal pressure, the material comprising the vessel is subjected to stresses acting in all directions. The normal stresses resulting from this pressure are functions of the radius and the shape of the pressure vessel, open ended cylinder, closed end cylinder as well as the applied pressure [3].

Furthermore it also needs to understand the significance of these stresses on the structural integrity of the pressure vessel by considering the material properties of the vessel [4]. In this

(C) 2018 Copyright held by the author(s). Published by AIJR Publisher in Proceedings of First Conference for Engineering

Sciences and Technology (CEST-2018), September 25-27, 2018, vol. 2.
This is an open access article under Creative Commons Attribution-NonCommercial 4.0 International (CC BY-NC 4.0)

license, which permits any non-commercial use, distribution, adaptation, and reproduction in any medium, as long as the original work is properly cited. ISBN: 978-81-936820-6-7 
context a major achievement in the theoretical foundation of the linear fracture mechanics was the introduction of the stress intensity factor (SIF) as a parameter for the intensity of stresses close to the crack tip. The stress intensity factor $\left(\mathrm{K}_{\mathrm{a}}\right)$ is compared with the critical stress intensity factor $K_{I C}$ (material fracture toughness) to determine whether or not the crack will propagate. This fracture parameter depends on size, shape and location of the defect; the applied load and geometry of the structure [5]. The presence of cracks on the walls of a pressure vessel can severely reduce the strength of the vessel and can cause sudden failure at nominal tensile stresses less than the material's yield strength [6]. Therefore, to ensure the integrity of a structure when a crack is present, the designer should understand and adequately apply the mechanics of fracture, particularly the relation between applied stress, the flaw size and the fracture toughness.

For the purpose of developing the design philosophy and the related operational limitations of various approaches, the yielding strength of the vessel is used as the criterion of failure [7]. In this context, failure theories of Von-Mises, Tresca, and maximum principle stress in conjunction with software and finite element method are widely adopted to design pressure vessels [8]. In addition, the numerical analysis of thin walled pressure vessel design parameters, material properties and temperature are found effective tools, and the maximum stress criteria is in good agreement with Von-Mises criteria for the failure of pressure vessels [9]. The analysis method applied in this work is the thin-walled pressure vessels theory for a ratio of inner radius to wall thickness $r / t>10$.

\section{Materials}

The materials selected for pressure vessels for the present work are shown in Table 1[10-11].

Table 1. Mechanical properties and chemical composition of materials used.

\begin{tabular}{|c|c|c|c|c|c|c|c|c|c|}
\hline Material & $\begin{array}{c}\sigma_{\text {uts }} \\
\mathrm{MPa}\end{array}$ & $\begin{array}{c}\sigma_{\mathrm{y}} \\
\mathrm{MPa}\end{array}$ & $\begin{array}{c}\mathrm{C} \\
\%\end{array}$ & $\begin{array}{c}\mathrm{Cr} \\
\%\end{array}$ & $\begin{array}{c}\mathrm{Ni} \\
\%\end{array}$ & $\begin{array}{c}\mathrm{Cu} \\
\%\end{array}$ & $\begin{array}{c}\mathrm{Mn} \\
\%\end{array}$ & $\begin{array}{c}\mathrm{Mo} \\
\%\end{array}$ & $\begin{array}{c}\mathrm{Si} \\
\%\end{array}$ \\
\hline SS 316L & 482 & 172 & 0.03 & 16 & 14 & - & 2 & 2.5 & 0.75 \\
\hline A 283-GR.C & 455 & 207 & 0.24 & - & - & 0.2 & 0.9 & - & 0.4 \\
\hline SS 304N & 551 & 241 & 0.03 & 18 & 8 & - & 2 & - & 0.75 \\
\hline A106-GR.C & 485 & 276 & 0.30 & 0.4 & 0.4 & 0.4 & 0.67 & 0.15 & 0.1 \\
\hline
\end{tabular}

\section{Pressure Vessel Design Procedure}

\subsection{Stresses Developed in Thin-Walled Pressure Vessels}

Thin-walled pressure vessels provide an application of the analysis of plane stress condition. The stresses developed due to the hydrostatic pressure are longitudinal stress (axial) $\sigma_{\mathrm{L}}$ and hoop stress $\sigma_{\mathrm{h}}$ in the circumference direction. The analysis of stresses in thin-walled pressure vessels will be limited to cylindrical pressure vessels as these are used widely and easy to 
Analysis of the Failure of Cylindrical Pressure Vessels

manufacture in contrast to spherical vessels. For a cylindrical pressure vessel shown in Figure 1 with length "L", radius " $r$ " and thickness " $t$ ", the stress $\sigma_{\mathrm{L}}$ in the axial direction of a cylindrical vessel with closed ends is[12]:

$\sigma_{L}=\frac{p . r}{2 . t}$

The hoop stress $\sigma_{\mathrm{H}}$, acts in the vessel wall in the circumferential direction can be written as:

$\sigma_{H}=\frac{p \cdot r}{t}$

Note that the hoop stress is twice the axial stress.
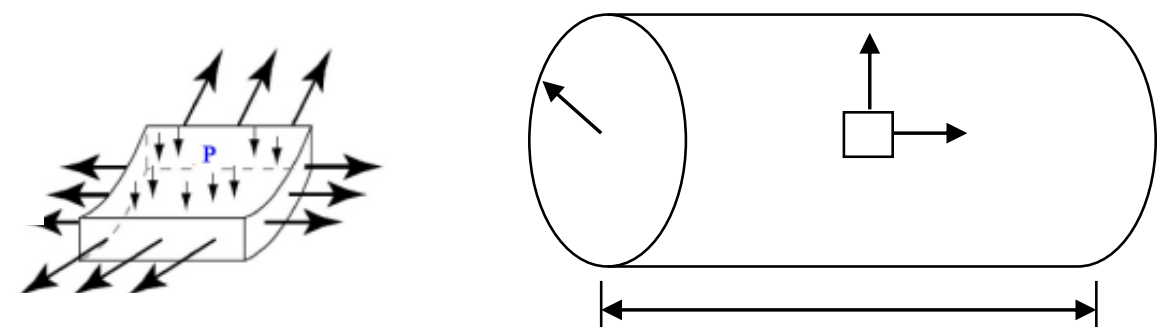

Figure 1: Longitudinal and hoop stresses in a cylindrical closed-end vessel.

\subsection{Code Selection}

There are many engineering standards which give information on the design. It is emphasized that any standard selected for manufacture of the pressure vessels must be followed and complied with in entirety and the design must not be based on provisions from different standards [13]. The ASME is normally followed cross the world, but other national or international standards may also be used. For this design, ASME VIII (division 2) "Construction of Pressure vessel Codes" are selected.

\subsection{Implementation of ASME Code (section VIII-division 2)}

The minimum thickness or maximum allowable working pressure of cylindrical shells shall be the greater thickness or lesser pressure as given by (3) or (4).

\section{Circumferential Stress (Longitudinal joints)}

When the thickness does not exceed one-half of the inside radius, or P does not exceed 0.385SE, the following formulas shall apply [14]:

$$
t=\frac{P R}{S E-0.6 P} \quad \text { or } \quad P=\frac{S E t}{R+0.6 t}
$$


Where $R$ is the inside radius, $t$ is the shell thickness, $E$ is the welded joint efficiency, $S$ is the material strength, $P$ is internal pressure.

\section{Longitudinal Stress (Circumferential joints)}

When the thickness does not exceed one-half of the inside radius, or P does not exceed 1.25SE, the following formulas shall apply[14]:

$t=\frac{P R}{2 S E+0.4 P} \quad$ or $\quad P=\frac{2 S E t}{R-0.4 t}$

\section{Failure Assessment Analysis}

\subsection{Yielding Criterion}

Yielding criterion of Von-Mises is applied in order to assess the integrity of the pressure vessels considered in this study. In von-Mises theory of failure, the yielding occurs when the vonMises stress $\sigma_{\mathrm{v}}$ is equal to the yielding stress [15]:

$\sigma_{v}=\sqrt{\sigma_{1}^{2}-\sigma_{1} \cdot \sigma_{2}+\sigma_{2}^{2}}=\sigma_{y}$

Where, $\sigma_{1}=\sigma_{\mathrm{H}}$ is hoop stress, and $\sigma_{2}=\sigma_{\mathrm{L}}$ is longitudinal stress, and $\sigma_{\mathrm{y}}$ is yielding strength.

\subsection{Fracture Mechanics Criterion}

The cracked cylindrical pressure vessel subjected to a longitudinal crack considered for the present work is shown in Figure 2.
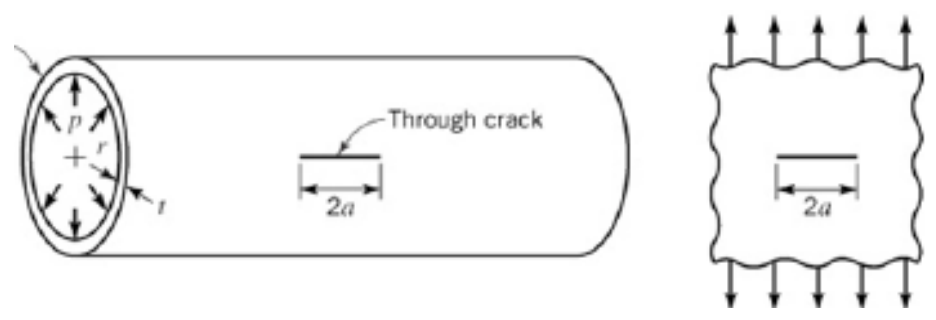

Figure 2: A cylindrical pressure vessel with a longitudinal crack.

The corresponding fracture stress $\sigma_{\mathrm{f}}(\mathrm{MPa})$ required propagating the crack is [16]:

$\sigma_{f}=\frac{K_{I c}}{\sqrt{\pi \cdot a} c}$ 
Analysis of the Failure of Cylindrical Pressure Vessels

Where, $\mathrm{K}_{\mathrm{Ic}}\left(\mathrm{MPa} . \mathrm{V}_{\mathrm{m}}\right)$ is the material fracture toughness, and "a" is the crack length. This can also be re-written in terms of the applied stress intensity factor $\left(\mathrm{K}_{\mathrm{a}}\right)$, and the crack propagates when:

$K_{a}=\frac{p \cdot r}{t} \cdot \sqrt{\pi \cdot a} \geq K_{I c}$

\subsection{Software Developed}

A computer program has been constructed and used to assess the integrity of cracked and uncracked pressure vessels. The program is based on the von-Mises theory and fracture mechanics method by considering the von-Mises stress, yielding strength, critical fracture toughness and critical crack depths. Figure 3 shows the front window of the program where the input data are: crack depth (a), internal pressure (p), shell thickness ( $\mathrm{t}$ ), vessel radius (r), and $\left(\mathrm{K}_{\mathrm{Ic}}\right)$. The output results are the von-Mises stress $\left(\sigma_{\mathrm{v}}\right)$ which is compared with the yielding strength, and fracture stress $\left(\sigma_{\mathrm{f}}\right)$ as a function of the fracture toughness and crack depth, and applied stress intensity factor $\left(\mathrm{K}_{\mathrm{a}}\right)$.

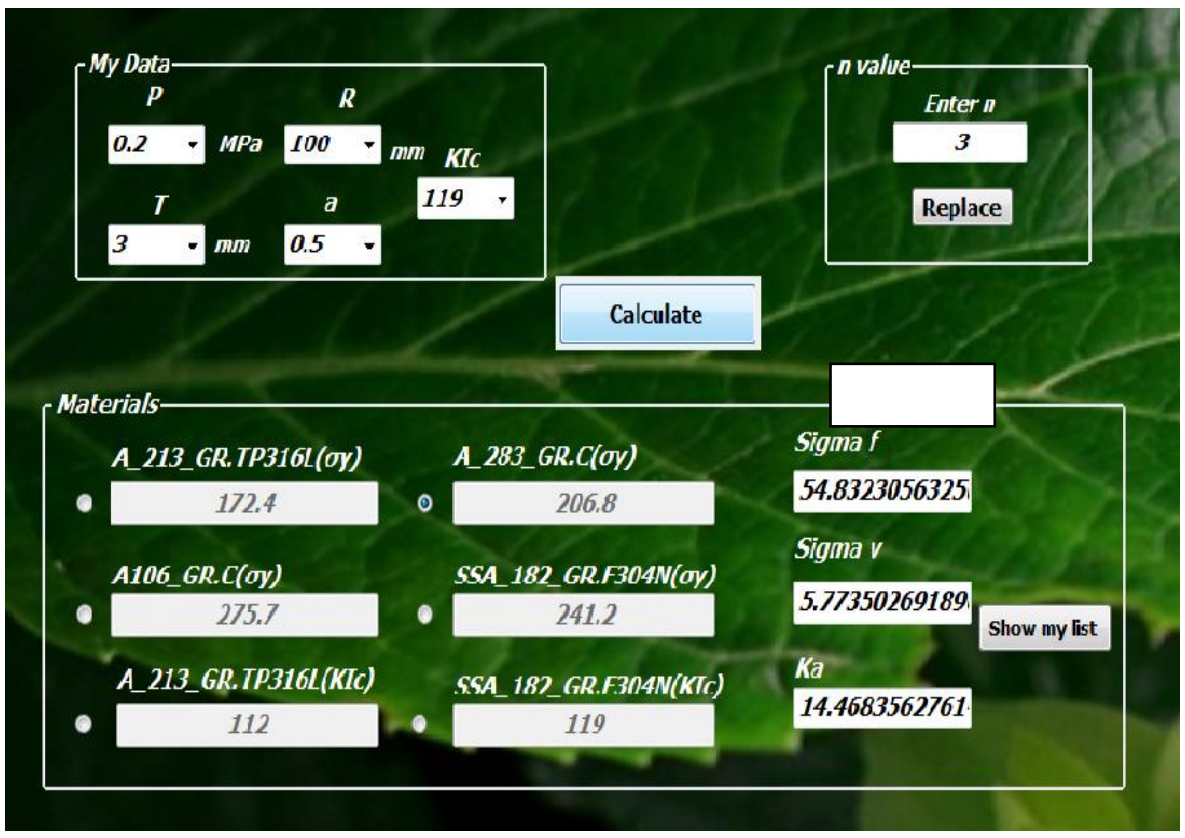

Figure 3: $A$ view for the input and output data of the program.

\section{$5 \quad$ Results and Discussion}

Figure 4 shows the von-Mises stress $\left(\sigma_{v}\right)$ as a function of vessel diameter for different shell thicknesses. The figure shows very conservative results with factor of safety greater than one $\left(\sigma_{\mathrm{y}}>\sigma_{\mathrm{v}}\right)$. It is shown that the yielding does not occur for all materials considered in this study for vessels diameters of 200 to 1000 for shell thickness $3 \mathrm{~mm}$ to $20 \mathrm{~mm}$ under designed pressure varies between (14.5psi-130.5psi) 100 to $900 \mathrm{KPa}$. 


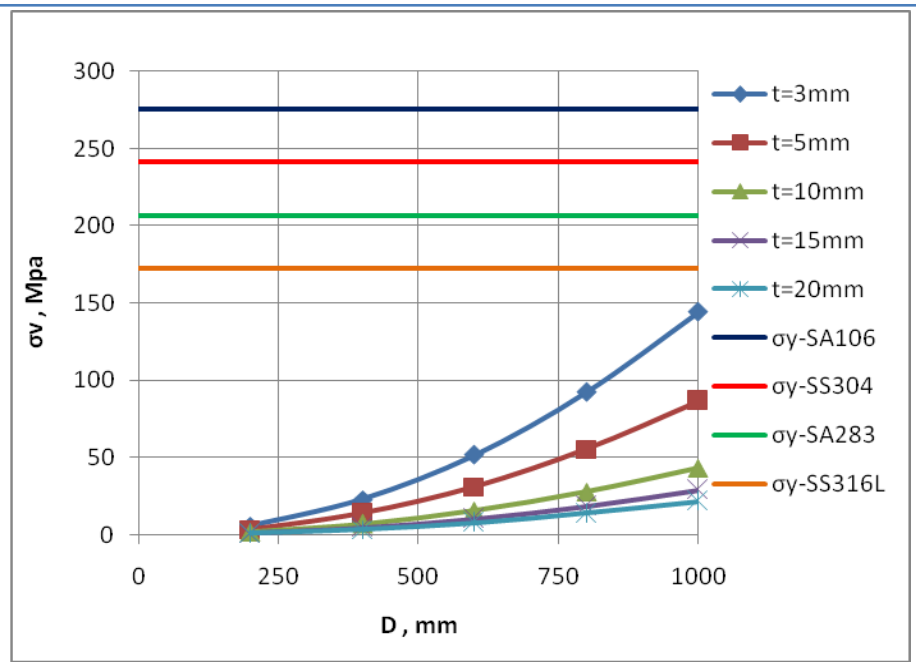

Figure 4: The von-Mises stress $\left(\sigma_{v}\right)$ as a function of vessel diameter and thickness.

Figure 5 shows pressure vessels yield criterion using factor of safety of 2 . For shell thickness of $5 \mathrm{~mm}$ or greater, all used materials are safe for diameters from $200 \mathrm{~mm}$ to $1000 \mathrm{~mm}$, while vessels with shell thickness of $3 \mathrm{~mm}$ are safe as long as the diameter less than $800 \mathrm{~mm}$.

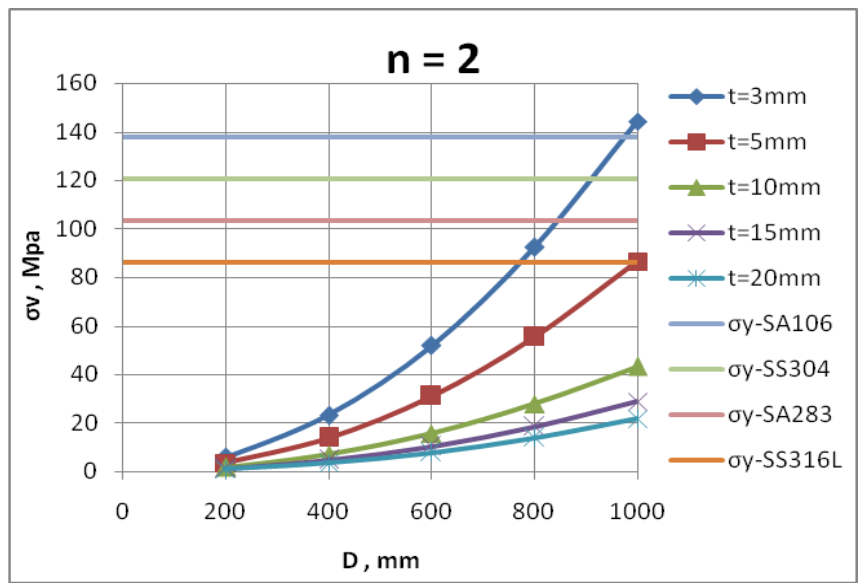

Figure 5: Pressure vessels yield criterion using factor of safety of 2.

Figure 6 shows the assessment of the pressure vessel in terms of applied stress intensity factor $\left(\mathrm{K}_{\mathrm{a}}\right)$ and the material fracture toughness $\left(\mathrm{K}_{\mathrm{Ic}}\right)$ of SS A-F304N with material strength of $241.2 \mathrm{MPa}$ and fracture toughness of $\mathrm{K}_{\mathrm{Ic}}=119 \mathrm{MPa} . \mathrm{V}_{\mathrm{m}}$, for a crack length $(\mathrm{a}=0.5 \mathrm{t}$ ). It is shown that thin pressure vessels with 3 and $5 \mathrm{~mm}$ thickness can be run safely under a considered pressure of ( 1 to 9 bar) for vessel diameters less than $600 \mathrm{~mm}$ for a crack depth less than 0.5 t. For thicker vessels, bigger vessels can be made from this type of material. 


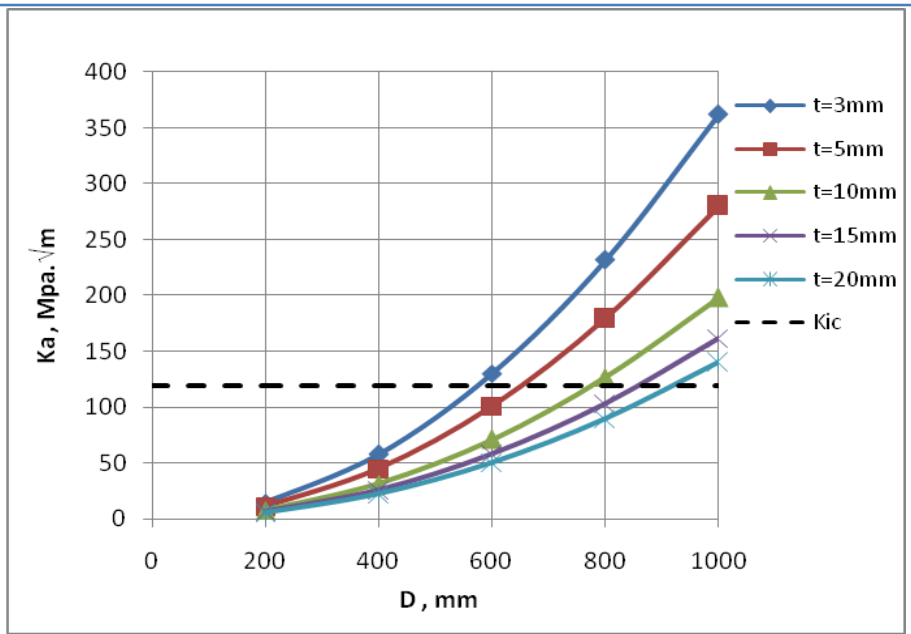

Figure 6: The applied stress intensity factor as a function of vessel diameter for $a=0.5 t$.

Figure 7 shows the assessment of the cracked pressure vessel made of SS F304N of material strength of $241.2 \mathrm{MPa}$ and $\mathrm{k}_{\mathrm{Ic}}=119 \mathrm{MPa} . V_{\mathrm{m}}$, based on a crack depth $(\mathrm{a}=0.2 \mathrm{t})$. The assessment is considered safe when values of the applied stress intensity factor $\left(K_{a}\right)$ are less than the fracture toughness of the material $\left(\mathrm{k}_{\mathrm{Ic}}\right)$. Therefore, vessels with diameters ranges from $200 \mathrm{~mm}$ to $1000 \mathrm{~mm}$ are safe as long as their thickness is greater than $10 \mathrm{~mm}$. However, thinner vessels having 3 and $5 \mathrm{~mm}$ thickness can be operated safely under a pressure considered for vessel diameters less than $720 \mathrm{~mm}$ for a crack depth less than $0.2 \mathrm{t}$.

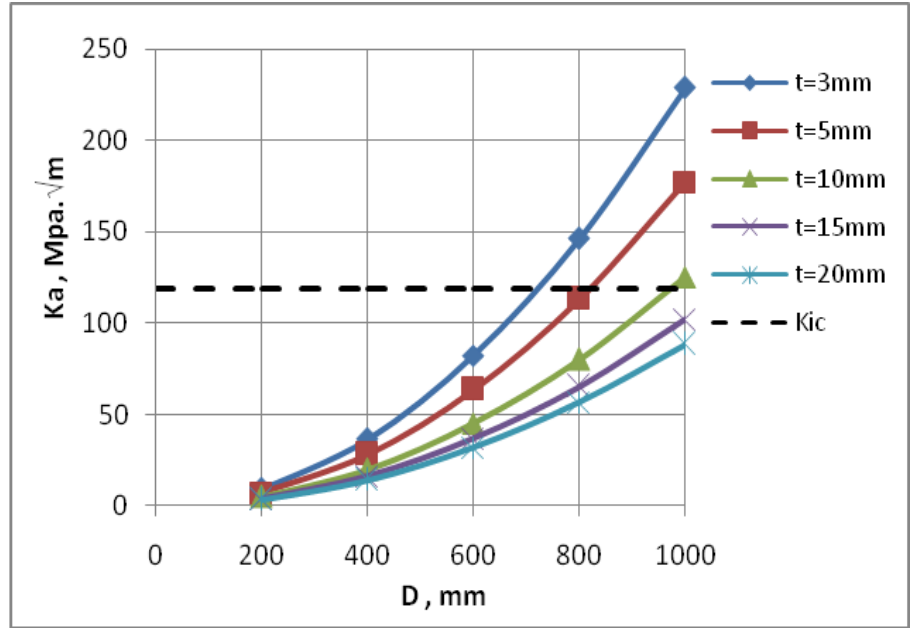

Figure 7: Applied stress intensity factor as a function of vessel diameter for $a=0.2$.

Figure 8 shows the applied stress intensity factor for cracked pressure vessels of $(a=0.5 t)$, made of SS316L of $\mathrm{k}_{\mathrm{Ic}}=112 \mathrm{MPa} . \sqrt{\mathrm{m}}$. It is shown that cracked vessels are safe as long as the crack depth is less than $0.5 \mathrm{t}$ for specific vessel diameter and thickness. For example, cracked vessels with diameters of $600 \mathrm{~mm}$ are safe with thickness greater than $5 \mathrm{~mm}$. 
Terfas et al., CEST-2018, AIJR Proceedings 4, pp.571-580, 2018

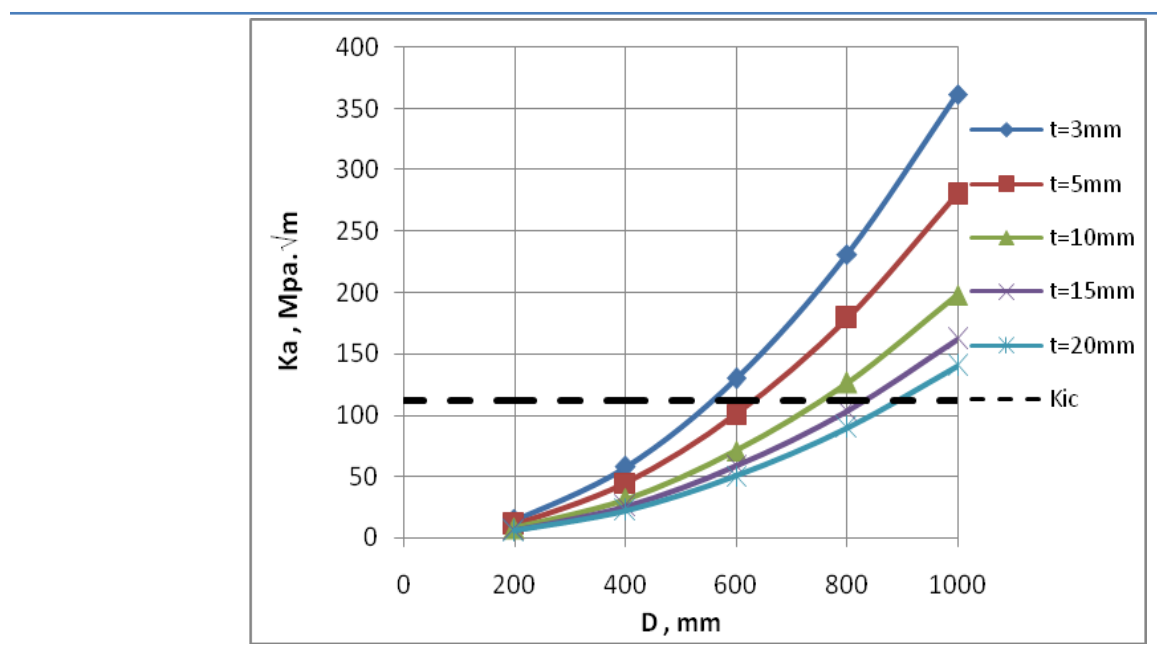

Figure 8: Applied stress intensity factor as a function of vessel diameter for $a=0.5 t$.

Figure 9 shows the applied stress intensity factor for cracked pressure vessels of $(a=0.2 t)$, made of SS316L with $K_{I c}=112 \mathrm{MPa} . V_{\mathrm{m}}$. It is obvious that the majority of $\mathrm{K}_{\mathrm{a}}$ values are below the horizontal line of $K_{I c}$ which means these vessel sizes are safe except for thin vessels ( $t=3$, $5 \mathrm{~mm})$ with large vessel diameter $(\mathrm{D}=700,1000 \mathrm{~mm})$.

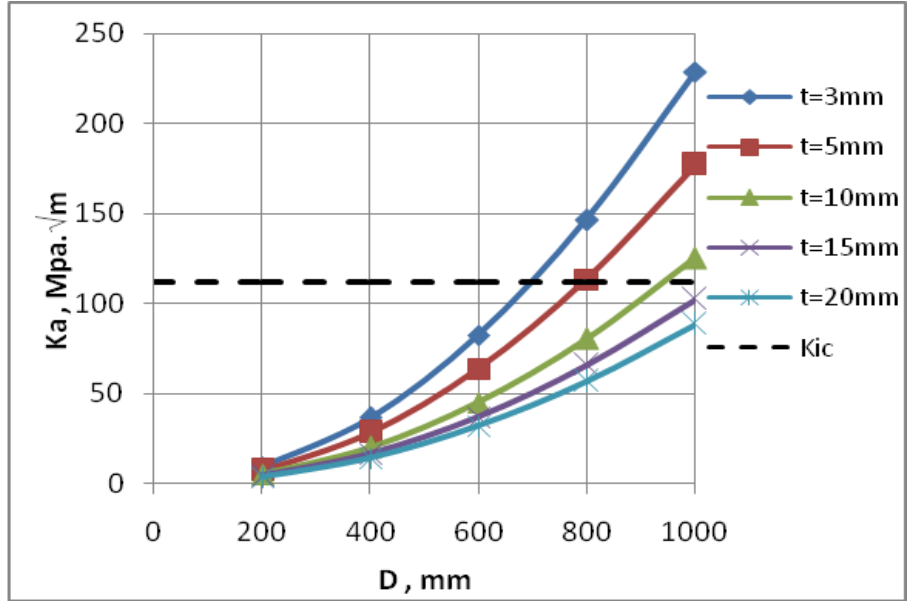

Figure 9: Applied stress intensity factor as a function of vessel diameter for $a=0.2 t$.

Figure 10 shows the fracture stress as a function of crack length. This figure is used in conjunction with Figures 11 and 12 to determine the fracture stress required to propagate the crack, critical crack length and maximum pressure. The SS304 steel vessel having diameter of $1000 \mathrm{~mm}$, shell thickness of $15 \mathrm{~mm}$ and $20 \mathrm{~mm}$ is safe under maximum pressure of 9bar when the crack length is less than $6 \mathrm{~mm}$. For vessels of $10 \mathrm{~mm}$ thickness, the largest acceptable crack length is $3 \mathrm{~mm}$. However, vessels with shell thickness of $5 \mathrm{~mm}$ are not safe under a pressure of $9 \mathrm{bar}$, unless the pressure is reduced below $5 \mathrm{bar}$ for $(\mathrm{a}<2 \mathrm{~mm})$. For vessel diameters of 500, the shell thickness of $5 \mathrm{~mm}$ is safe as long as the crack length is less than $3 \mathrm{~mm}$ at the maximum pressure used.

Proceedings of First Conference for Engineering Sciences and Technology (CEST-2018), vol. 2 


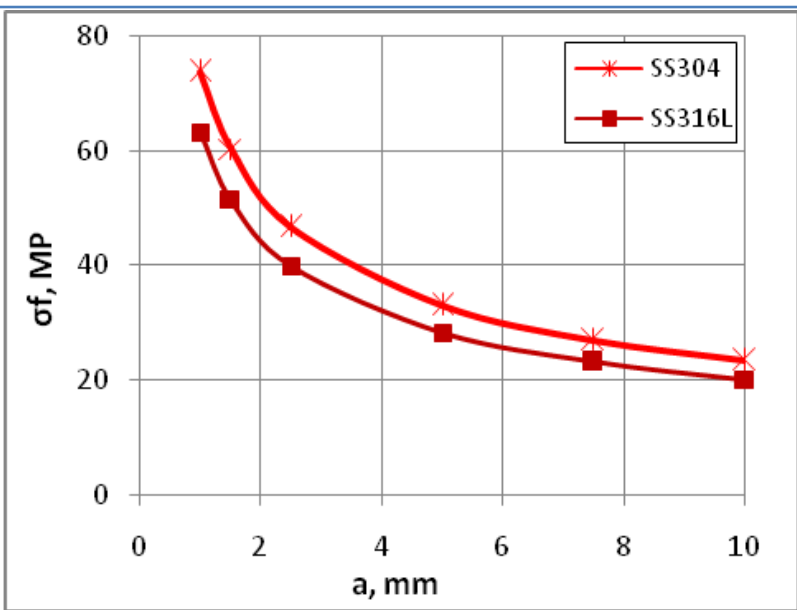

Figure 10: Fracture stress as a function of crack length for steel used.

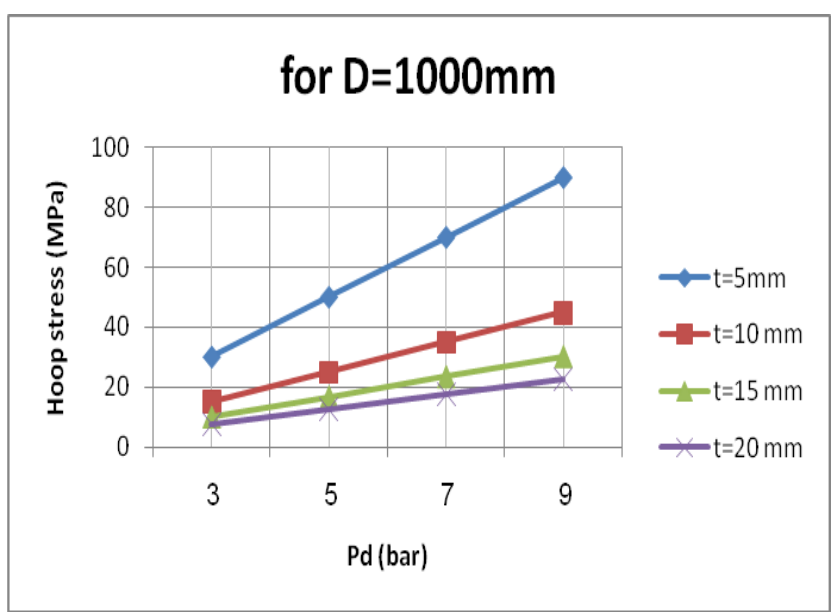

Figure 11: Hoop stress as a function in design pressure for vessel diameter of $1000 \mathrm{~mm}$.

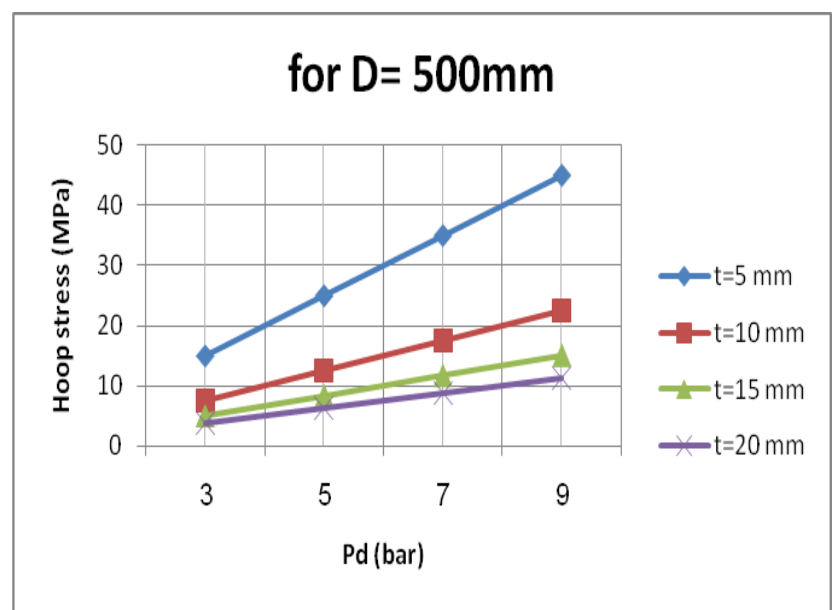

Figure 12: Hoop stress as a function in design pressure for vessel diameter of $500 \mathrm{~mm}$. 
Terfas et al., CEST-2018, AIJR Proceedings 4, pp.571-580, 2018

For SS316L, a vessel with diameter of $1000 \mathrm{~mm}$ and the shell thickness of $5 \mathrm{~mm}$ is safe if pressure reduced below 6bar and the crack length is less than $1.5 \mathrm{~mm}$. For $10 \mathrm{~mm}$ thickness the largest acceptable crack length is $2 \mathrm{~mm}$ under pressure of $9 \mathrm{bar}$. However, for pressure less than 6bar cracked pressure vessels with diameter of $1000 \mathrm{~mm}$ and shell thickness of $15 \mathrm{~mm}$ and $20 \mathrm{~mm}$ are safe as long as crack length is shorter than $7.5 \mathrm{~mm}$ and $10 \mathrm{~mm}$ respectively. For vessel diameters of 500 with shell thickness of $5 \mathrm{~mm}$ is safe as long as the crack length is less than $2 \mathrm{~mm}$ at the maximum pressure. While for $10 \mathrm{~mm}$ thickness the vessel is safe as long as the crack length is less than $5 \mathrm{~mm}$.

\section{Conclusions}

This research investigated the effects of design parameters in terms of material strength and internal pressure on the integrity of pressure vessels. Both yielding criterion of von-Mises, and fracture stress theory were used to assess the integrity of pressure vessels. The von-Mises stress $\left(\sigma_{v}\right)$ method showed that all materials used in this study are safe for dimensions and thicknesses considered and ensures factor of safety greater than one. However, for factor of safety of 2 only a very thin vessel with $\mathrm{t}=3 \mathrm{~mm}$ and $\mathrm{D}>800 \mathrm{~mm}$ is subjected to yielding. In the presence of a crack with the length of $(0.2 \mathrm{t})$ vessels with diameters greater than $700 \mathrm{~mm}$ associated with thickness less than $10 \mathrm{~mm}$ become unsafe. However, vessels with diameters ranges from $200 \mathrm{~mm}$ to $1000 \mathrm{~mm}$ with thickness of $15 \mathrm{~mm}$ and $20 \mathrm{~mm}$ are safe under considered conditions.

\section{References}

[1] Somnath Chattopadhyay, Pressure Vessels: Design and Practice, CRC press, 2005.

[2] Ahmed Ibrahim, Yeong Ryu, Mir Saidpour, Stress Analysis of Thin Walled Pressure Vessels, Modern Mechanical Engineering, Scintific Research Publishing, V5, 01-09, 2015.

[3] Busuioceanu Paraschiva, Stefanescu Florentinab, Ghencea Adrianc, Study of Stresses and Stress Concentrations in Pressure Vessels, Journal of Bussiness economics and Information Technology, V3, 2016.

[4] Dennis H. Moss, Pressure Vessel Design Manual. 3rd edition, Elsevier, 2004.

[5] Kuna, M. Finite Elements in Fracture Mechanics: Theory - Numerics - Applications (Solid Mechanics and Its Applications, 2013.

[6] S. Kotrechko,Yu. Meshkov, A new approach to estimate irradiation embrittlement of pressure vessel steels, pressure vessel and piping, 2007.

[7] Analysis of a thick and thin walled pressure vessel for different materials. Qayssar S. Masikh, Mohammad Tariq, Prabhat K. Sinha. International Journal of Mechanical Engineering and Technology, V5, 09-19, 2014.

[8] Thin Z. Hlaing, Htay H. Win, Failure Analysis of A Thin-walled CNG Cylindrical Pressure vessel, International Journal of Scientific Engineering and Technology Research, V3, 1874-1879, 2014.

[9] Özmen S. Eruslu, Sencer S. Karabeyodlu, Failure Analysis of thin Walled Pressure Vessels, International Scientific Conference, Gabrovo, 22-24 Nov. 2007.

[10] Carbon Steel Handbook, Electric Power Research Institute (EPRI), Palo Alto, CA: 2007.

[11] Stainless Steel Grade Datasheet, Atlas Steel Technical Department, 2013.

[12] Apurva P., Mahesh G., Nitin D., Rajkumar P., Design and analysis of pressure vessel, International Journal of Innovative Research in Technology \& Science(IJIRTS), V2, 28-34, 2013.

[13] B.S.Thakkar, S.A.Thakkar, Design of pressure vessel using ASME code Section VIII, Division-1, International Journal of Advanced Engineering Research and Studies, 2012.

[14] ASME-VIII Code, Division 2, Boiler and Pressure Vessel, Alternative Rules for Construction Pressure Vessels, 2010.

[15] Hibbeler, C., Mechanics of materials, 8th edition, prentice hall (pearson), 2011.

[16] Anderson, T. L. Fracture Mechanics: Fundamentals and Applications, Third Edition. CRC Press, 2012.

Proceedings of First Conference for Engineering Sciences and Technology (CEST-2018), vol. 2 